\title{
THE PACING OF MIXED MARTIAL ARTS SPARRING BOUTS: A SECONDARY INVESTIGATION WITH NEW ANALYSES OF PREVIOUS DATA TO SUPPORT ACCELEROMETRY AS A POTENTIAL METHOD OF MONITORING PACING
}

original paper

( $)$ University School of Physical Education in Wroclaw

DOI: https://doi.org/10.5114/hm.2020.94194

\author{
CHRISTOPHER KIRK ${ }^{1,2}$, STEPHEN ATKINS ${ }^{3}$, HOWARD T. HURST ${ }^{4}$ \\ ${ }^{1}$ College of Life and Natural Sciences, University of Derby, Derby, United Kingdom \\ ${ }^{2}$ Research Institute for Sport and Exercise Sciences, Liverpool John Moores University, Liverpool, United Kingdom \\ ${ }^{3}$ University of Salford, Salford, United Kingdom \\ ${ }^{4}$ University of Central Lancashire, Preston, United Kingdom
}

\begin{abstract}
Purpose. Body-worn accelerometry has been shown to be reliable and used to measure the external load of mixed martial arts (MMA) via the Playerload metric. These measurements were only reported on a round-by-round basis, offering little indication of minute-by-minute load changes. Understanding these changes may provide a proxy measure of fatigue, readiness, and the onset of non-functional overreaching. It is also unclear as to what Playerload is measuring in MMA. This study was a secondary investigation of previously reported data to describe minute-by-minute changes in external load in MMA. Methods. Six male MMA competitors participated in a $3 \times 5$ minute sparring bout wearing a Catapult Minimax $\times 3$, which recorded accumulated Playerload. The bouts were video-recorded. Time-motion analysis was used to determine: total active time; total inactive time; high-intensity time; low-intensity time; standing time; grounded time; striking time; non-striking time.
\end{abstract}

Results. Bayesian repeated measures ANOVA found statistically relevant differences in accumulated Playerload for each minute of sparring $\left(\mathrm{BF}_{10}=410\right)$ with no statistically relevant differences between winners and losers. Bayesian correlations revealed a direct, nearly perfect relationship between accumulated Playerload and total active time $\left(r=0.992, \mathrm{BF}_{10}=9,666\right)$. No other relationships between Playerload and time-motion analysis results were observed, despite Bayesian t-tests finding differences between standing time and grounded time $\left(\mathrm{BF}_{10}=83.7\right)$, striking time and non-striking time $\left(\mathrm{BF}_{10}=1,419\right)$.

Conclusions. Playerload reflects overall active movement in MMA and measures active movement minute-by-minute changes but cannot distinguish between different modes or intensities of movement. This should be investigated further as a potential measure of fatigue and non-functional overreaching during MMA training.

Key words: mixed martial arts, pacing, Playerload, combat sports

\section{Introduction}

Pacing within sports performance has been highlighted as an important consideration for success across several sports, with the focus being primarily in endurance or steady-state events [1-4]. The measurement of pacing and onset of fatigue can be more inconsistent in intermittent or open-skill sports, where physiological measures are not steady-state and are heavily affected by physical contact and other external factors [5]. This is particularly true of activities that are not entirely ambulatory, such as striking- and grap- pling-based combat sports, where distances covered, velocities, and durations are of little importance $[6,7]$. As pacing strategies are employed to negate the effects of fatigue during performance, understanding the causes of fatigue and its effects on a specific activity is an important step. Unfortunately, measuring these physiological loads in combat sports in an ecologically valid and training-applicable manner has proven difficult. This has led to proxy measures primarily being used [8-10].

Within mixed martial arts (MMA), the most relied upon proxy measure has been time-motion analysis

Correspondence address: Christopher Kirk, University of Derby, College of Life and Natural Sciences, Kedleston Rd., Derby, United Kingdom, DE22 1GB, e-mail: C.Kirk@Derby.ac.uk

Received: August 16, 2019

Accepted for publication: November 29, 2019

Citation: Kirk C, Atkins S, Hurst HT. The pacing of mixed martial arts sparring bouts: a secondary investigation with new analyses of previous data to support accelerometry as a potential method of monitoring pacing. Hum Mov. 2020;21(4):88-96; doi: https://doi.org/10.5114/hm.2020.94194. 
(TMA), which has been used extensively to determine work-to-rest ratios (W:R) and key actions applied in competition [11-13]. TMA has been used to suggest the pacing of MMA bouts, with actions and movements reducing in the final round [6]. This method is, however, time-consuming and owing to the subjective nature of which actions are defined as 'work' and 'rest,' might not provide the most robust assessment of pacing. Additionally, any pacing assessment method used should be applicable within a training environment if it is to have any genuine impact in the field. Accelerometry has been suggested as a potential solution for this issue in other combat sports $[14,15]$. The Catapult Playerload metric has been shown to be reliable in the measurement of isolated MMA movements [16] and subsequently applied to measure the external load of MMA sparring bouts [17]. From these sparring bouts, the accumulated Playerload $\left(\mathrm{PLd}_{\mathrm{ACC}}\right)$ and the accumulated Playerload per minute $\left(\mathrm{PLd}_{\mathrm{ACC}} \cdot \mathrm{min}^{-1}\right)$ of MMA were determined. These were only reported on a roundby-round basis, however, without any more detailed analysis provided. This means the potential role of accelerometry in determining the pacing of an MMA bout, or the differences in pacing between bout winners and losers, has not been explored. This may be a key area of research to improve the training-based performance assessment of MMA competitors. This in turn could potentially allow the quantification of readiness and the onset of non-functional overreaching in this population, where there is currently no readily available method of measuring a reduction in performance [18].

Questions have been raised regarding what is actually being measured by accelerometry for ambulatory and contact sports. Ground reaction forces as a confounding variable and weak relationships to other markers of intensity and load have been highlighted as key issues [19-21]. Understanding which aspects of performance are actually underpinning a particular measurement is a requirement of its acceptance.

Currently, no previous studies have explored the relationship between accelerometry data and other markers of intensity in MMA. With accelerometry data already existing from previous experimental procedures [17], it would be resource- and cost-effective to perform exploratory analyses on these data to assess whether or not it would be reasonable to design and implement large cohort experiments. Provision of results from these analyses to other research groups would allow more studies to be completed with a greater overall sampling of the MMA population. Therefore, it was decided that performing a secondary investi- gation with new analyses on the data from the Kirk et al. [17] study might provide some insight as to whether or not there are grounds for accelerometry to be investigated further as an assessment method for bout pacing, fatigue, and readiness.

The aim of this study was to conduct exploratory, secondary analyses on existing data to inform the direction of future large cohort studies into accelerometry use in the measurement of pacing in MMA. For this purpose, two hypotheses were established for the current study: (1) accelerometry could measure acute changes in pacing during MMA sparring bouts; (2) accelerometry data share a relationship with other measures of intensity during MMA sparring bouts.

\section{Material and methods}

NB. The following section has been adapted from the methods section of the original article [17].

\section{Participants}

Six male MMA trained competitors $(n=6$, age: $26.17 \pm 5.04$ years, stature: $176.50 \pm 5.86 \mathrm{~cm}$, mass: $73.33 \pm 7.84 \mathrm{~kg}$ ) took part in the study. In order for the participants to be eligible for the study, they must have taken part in at least 4 professional or semi-professional MMA bouts at either regional or national standard, whilst one of their bouts must have occurred in the 6 months prior to the day of testing. All participants were provided a familiarisation session prior to testing and were instructed to refrain from alcohol for two days before the test and to eat a breakfast that would be typical for a competition day.

\section{Materials}

The participant's stature was measured to within $0.5 \mathrm{~cm}$ by using a Leicester Height Measure stadiometer (Seca, Birmingham, UK) and their mass was measured to the nearest $0.5 \mathrm{~kg}$ with standard manual scales (Seca, Birmingham, UK). The participants were equipped with 198-g MMA sparring gloves, kickboxing shin and instep pads, standard MMA competition shorts, a groin protector, gum shield, and a T-shirt or rash guard. They were each fitted with a Minimax X3 100-Hz triaxial accelerometer (Catapult Innovations, Australia), which was calibrated in accordance with the manufacturer's specifications and placed in a support harness on the participant's back around the T3-4 vertebrae. The harness was then secured in place with duct tape around the participant's torso. 
C. Kirk, S. Atkins, H. Hurst, A method to measure the pacing of mixed martial arts

\section{Protocols}

Each participant took part in a single sparring bout in a 17-foot diameter competition standard MMA cage under MMA rules modified for the participant's safety $(3 \times 5$ minute rounds, 1 -minute rest between rounds, no elbows or knees to the head) against another participant who measured a similar mass on the day of testing. Each individual took part in 1 bout, providing a sample of 6 participants and 3 bouts in total. The bouts were video-recorded in their entirety by using a tripod-based Samsung HMX-F80 camcorder (Samsung, Seoul, South Korea). At the end of the bout, two independent MMA coaches with competition judging experience viewed the bouts once separately in isolation. They then agreed who would have been declared the winner and loser if the bout had been an official contest.

\section{Time-motion analysis}

The sparring bouts were viewed in their entirety and TMA was completed for each participant individually with the use of LongoMatch 0.18 (Andoni Morales, Madrid, Spain) tagging software. The time in seconds (s) spent in each of the variables listed below was recorded. The variables were split into either high-intensity actions or low-intensity actions, on the basis of previously published instantaneous Playerload (PLd - the external load of an individual movement or action) measurements of the movements involved [22] and discussions with an independent MMA coach about what they anecdotally viewed as more or less intense actions. The total time the cohort spent performing each action was used to calculate each participant's total active time (TAc), total inactive time (TIn), total high-intensity time (THI), total low-intensity time (TLI) and the ratio of THI to TLI (THI:TLI). The cohort's TAc spent in standing actions (TSta) and their TAc spent in grounded actions (TGr) were used to calculate the ratio between these two variables (TSta:TGr). The same procedure was performed between the cohort's mean TAc spent in striking actions (TStr) and mean TAc spent in non-striking actions (TNStr) to determine the ratio between these variables (TStr:TNStr). The TMA results were reviewed and verified by a second independent MMA coach.

THI variables: inferior position (participant is put into an inferior position either standing or on the ground); high activity striking (3 or more strikes per exchange whilst standing); clinch defending (participant did not instigate the clinch or is not controlling the clinch); takedown attempt (participant attempts to takedown opponent); takedown successful (participant successfully gets opponent to a grounded position); sprawl (participant drops their bodyweight rapidly forward to prevent a takedown); high activity ground strikes (3 or more strikes per exchange in a grounded position); sweep (participant moves from an inferior position on the ground directly to a dominant position); to standing (participant moves from a grounded position to standing whilst clinched); scramble (participants are both moving rapidly on the ground with neither having a direct advantage); submission attempt (participant attempts a submission); successful submission (participant submits opponent); submission defence (participant defends a submission attempt).

TLI variables: low activity striking (no more than 2 strikes per exchange whilst standing); clinch aggressor (participant instigates or is controlling a clinch); lockdown (both participants are grappling in a grounded position and are holding each other so neither can advance or strike); dominant position (participant secures a dominant position in either standing or grounded position); low activity ground strikes (no more than 2 strikes per exchange in a grounded position); clinch striking (striking within a clinch); pass attempt (participant attempts to pass from a neutral position into a more dominant position on the ground); pass (participant moves from a neutral position to a dominant position on the ground).

\section{Statistical analyses}

Within the Catapult Sprint 5.0.9 software (Catapult Innovations, Melbourne, Australia), the data from the sparring bout for each participant were split into 15 separate 1 -minute periods. The $\mathrm{PLd}_{\mathrm{ACC}}$ and the $\mathrm{PLd}_{\mathrm{ACC}} \cdot \mathrm{min}^{-1}$ at the end of each minute, round, and the bout as a whole were calculated.

Data normality was confirmed via Shapiro-Wilk test of normality $(p \geq 0.05)$. Bayesian repeated measures ANOVA $\left(\mathrm{BF}_{10}\right)$ and omega squared $\left(\omega^{2}\right)$ effect sizes were calculated for the $\mathrm{PLd}_{\mathrm{ACC}}$ and the $\mathrm{PLd}_{\mathrm{ACC}} \cdot \mathrm{min}^{-1}$ of each round, and for the PLd $\mathrm{AcC}_{\mathrm{AC}}$ of each minute of the sparring bouts. For each Bayesian repeated measures ANOVA completed, post-hoc comparisons were calculated using a default $t$-test with a Cauchy prior, whilst plots displaying means and 95\% credible intervals (95\% CI) were also produced.

To determine whether or not there were statistically relevant differences between the time spent in different phases of the bouts, Bayesian paired samples $t$-tests $\left(\mathrm{BF}_{10}\right)$ were conducted between THI and TLI; TSta and 
TGr; TStr and TNStr. The effect sizes for these tests were calculated using Cohen's $d$ with the standard deviation of the mean scores as the denominator. Plots displaying means and $95 \%$ CI were also produced for these variables.

Finally, to find evidence of any relationships be-

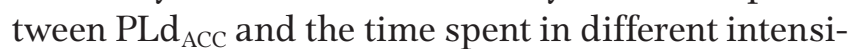
ties or bout phases, Bayesian Pearson correlation $\left(\mathrm{BF}_{10}\right)$ and, if required, Bayesian linear regression $\left(\mathrm{BF}_{10}\right)$ were calculated between PLd $\mathrm{ACC}_{\mathrm{C} C}$ and TAc; PLd $\mathrm{ACC}_{\mathrm{And}}$ and TIn; PLd $\mathrm{ACC}_{\mathrm{ACC}}$ and THI; PLd $\mathrm{ACC}_{\mathrm{ACC}}$ and TLI; PLd $\mathrm{ACC}_{\text {and TSta; }}$ and PLd $_{\mathrm{ACC}}$ and TGr; PLd $\mathrm{ACC}_{\mathrm{ACC}}$ and TStr; PLd $\mathrm{ACC}_{\mathrm{And}}$ TNStr.

The following thresholds were used for each of the $\mathrm{BF}_{10}$ related tests: 1-2.9 anecdotal; 3-9.9 moderate; $10-29.9$ strong; $30-99.9$ very strong; $\geq 100$ decisive [23]. For succinct presentation of findings, only $\mathrm{BF}_{10}$ results found to be moderate or greater are reported. Correlation thresholds were set at: trivial $r \leq$ 0.09; small $r \geq 0.1$; moderate $r \geq 0.3$; large $r \geq 0.5$; very large $r \geq 0.7$; nearly perfect $r \geq 0.9$; perfect $r=1$ [24]. The $\omega^{2}$ thresholds were set at: small $\omega^{2} \geq 0.01$; moderate $\omega^{2} \geq 0.06$; large $\omega^{2} \geq 0.14$ [25]. Cohen's $d$ thresholds were set at: trivial $d \leq 0.1$; small $d \geq 0.2$; moderate $d \geq 0.6$; large $d \geq 1.2$ [26]. Each of the named statistical tests was completed using JASP 0.9.2.0 (JASP Team, Amsterdam, Netherlands).

\section{Ethical approval}

The research related to human use has complied with all the relevant national regulations and institutional policies, has followed the tenets of the Declaration of Helsinki, and has been approved by the University of Central Lancashire Research Ethics SubCommittee.

\section{Informed consent}

Verbal and written informed consent has been obtained from all individuals included in this study.

\section{Results}

NB. As this paper is a reanalysis of previously published data, references have been placed where results are reproduced.

As can be seen in Table 1 , both PLd ACC $_{\text {and }}$ $\mathrm{PLd}_{\mathrm{ACC}} \cdot \mathrm{min}^{-1}$ displayed linear reductions in each successive round. Bayesian repeated measures ANOVA found the $\mathrm{PLd}_{\mathrm{ACC}}$ of each round to be anecdotally different with a large effect $\left(\mathrm{BF}_{10}=2.95, \omega^{2}=0.18\right)$, with a strong difference observed between round 1 and round 3 in post-hoc testing $\left(\mathrm{BF}_{10}=12.1\right)$ (Figure 1).
When comparing the $\mathrm{PLd}_{\mathrm{ACC}} \cdot \mathrm{min}^{-1}$ of each round, there was found to be an anecdotal difference with a large effect between the rounds $\left(\mathrm{BF}_{10}=2.9, \omega^{2}=0.17\right)$, but a strong difference between round 1 and round 3 according to post-hoc testing $\left(\mathrm{BF}_{10}=19\right)$ (Figure 2).

The mean $\pm S D$ of the PLd $_{\mathrm{ACC}}$ for each minute of the sparring bouts can be viewed in Table 2, whilst the means and 95\% CI are presented in Figures 3a and $3 \mathrm{~b}$. The Bayesian repeated measures ANOVA for this variable showed decisive differences between each minute with a large effect $\left(\mathrm{BF}_{10}=410, \omega^{2}=0.23\right)$.

Table 1. Mean $\pm S D$ accumulated Playerload $\left(\mathrm{PLd}_{\mathrm{ACC}}\right)$ and accumulated Playerload per minute of each round of sparring reproduced from Kirk et al. [17]

\begin{tabular}{ccc}
\hline Round & $\operatorname{PLd}_{\mathrm{ACC}}(\mathrm{au})$ & $\mathrm{PLd}_{\mathrm{ACC}} \cdot \mathrm{min}^{-1}(\mathrm{au})$ \\
\hline 1 & $77.61 \pm 9.92$ & $15.37 \pm 1.71$ \\
2 & $71.48 \pm 10.56$ & $14.30 \pm 2.11$ \\
3 & $65.39 \pm 8.61$ & $13.08 \pm 1.72$ \\
\hline
\end{tabular}

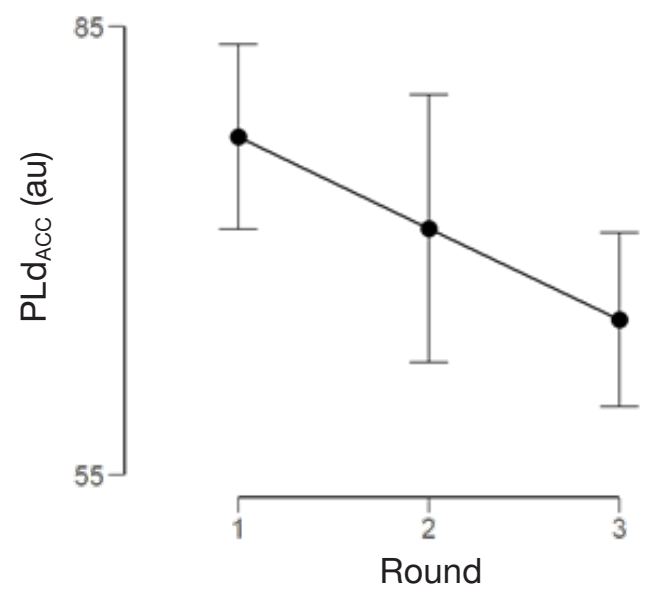

Figure 1. Accumulated Playerload (PLd $\left.\mathrm{ACC}_{\mathrm{A}}\right)$ by round (error bars - 95\% CI)

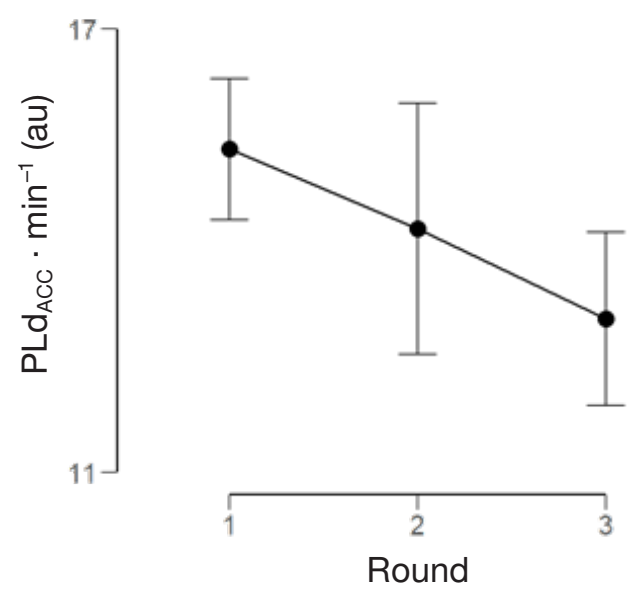

Figure 2. Accumulated Playerload per minute $\left(\mathrm{PLd}_{\mathrm{ACC}} \cdot \mathrm{min}^{-1}\right)$ by round (error bars $\left.-95 \% \mathrm{CI}\right)$ 


\section{HUMAN MOVEMENT}

C. Kirk, S. Atkins, H. Hurst, A method to measure the pacing of mixed martial arts

Table 2. Mean $\pm S D$ accumulated Playerload $\left(\mathrm{PLd}_{\mathrm{ACC}}\right)$ of each minute of sparring

\begin{tabular}{cc}
\hline Minute & $\operatorname{PLd}_{\mathrm{ACC}}(\mathrm{au})$ \\
\hline 1 & $15.51 \pm 2.1$ \\
2 & $15.08 \pm 2$ \\
3 & $14.91 \pm 2.5$ \\
4 & $14.72 \pm 2.7$ \\
5 & $16.65 \pm 2$ \\
6 & $15.7 \pm 2.7$ \\
7 & $13.96 \pm 1.5$ \\
8 & $15.46 \pm 1.9$ \\
9 & $13.3 \pm 3.4$ \\
10 & $13.1 \pm 3.5$ \\
11 & $15.3 \pm 1.9$ \\
12 & $14.5 \pm 1.4$ \\
13 & $11.7 \pm 2.1$ \\
14 & $13.82 \pm 4.5$ \\
15 & $10.1 \pm 2.3$ \\
\hline
\end{tabular}
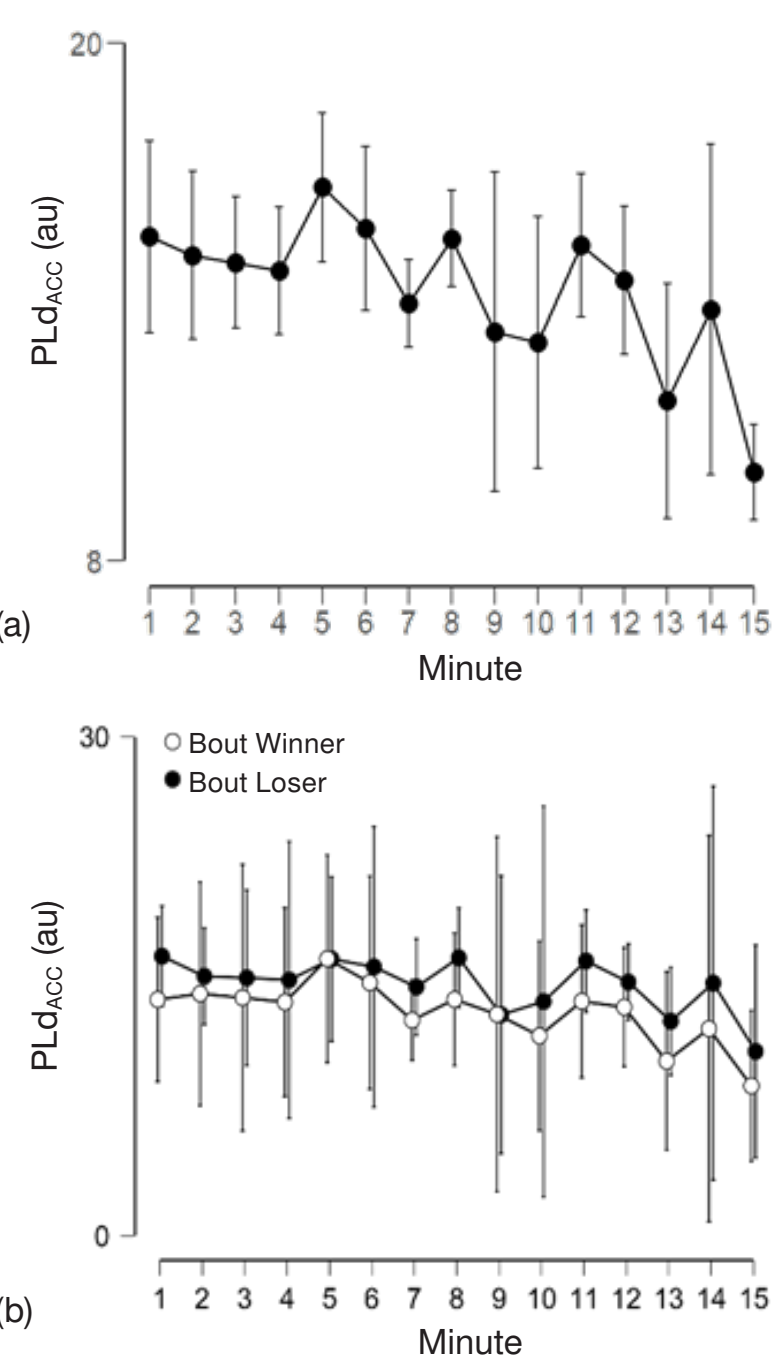

Figure 3. Accumulated Playerload $\left(\mathrm{PLd}_{\mathrm{AcC}}\right)$ of each minute of sparring (error bars - 95\% CI) displayed as full cohort (a) and grouped by bout winner/loser (b)
Post-hoc testing found the following minutes to display statistically different PLd $\mathrm{ACC}_{\mathrm{A}}$ to each other: 1 and $13\left(\mathrm{BF}_{10}=31.4\right.$, very strong $) ; 1$ and $15\left(\mathrm{BF}_{10}=22\right.$, strong); 2 and $13\left(\mathrm{BF}_{10}=10\right.$, strong); 2 and $15\left(\mathrm{BF}_{10}=\right.$ 22.7, strong); 3 and $15\left(\mathrm{BF}_{10}=160\right.$, decisive $) ; 4$ and 15 $\left(\mathrm{BF}_{10}=72\right.$, very strong); 5 and $15\left(\mathrm{BF}_{10}=183\right.$, decisive $)$; 6 and $10\left(\mathrm{BF}_{10}=7.2\right.$, moderate); 6 and $15\left(\mathrm{BF}_{10}=28\right.$, strong); 7 and $15\left(\mathrm{BF}_{10}=16.3\right.$, strong); 8 and $15\left(\mathrm{BF}_{10}=\right.$ 292, decisive); 11 and $15\left(\mathrm{BF}_{10}=19.6\right.$, strong); 12 and $13\left(\mathrm{BF}_{10}=3.5\right.$, moderate); 12 and $15\left(\mathrm{BF}_{10}=12.4\right.$, strong); 14 and $15\left(\mathrm{BF}_{10}=4.3\right.$, moderate).

The THI:TLI calculated from the TMA was 0.68:1, due to THI $=181.3 \pm 38.1 \mathrm{~s}$ and TLI $=266.3 \pm 59.6 \mathrm{~s}$. The TSta:TGr ratio was found to be $2.82: 1$, based on $\mathrm{TSta}=330.5 \pm 54.7 \mathrm{~s}$ and $\mathrm{TGr}=117.2 \pm 10.9 \mathrm{~s}$. The calculation of TStr:TNStr was determined to be $0.4: 1$, from TStr $=128.5 \pm 24.7 \mathrm{~s}$ and TNStr $=319.2 \pm 30.3 \mathrm{~s}$.

Bayesian paired samples $t$-tests found a decisive difference between TStr and TNStr with a large effect $\left(\mathrm{BF}_{10}=1,419, d=7.2\right)$. There was also a very strong difference between TSta and TGr with a large effect $\left(\mathrm{BF}_{10}=83.7, d=3.4\right)$. The difference between THI and TLI was observed to have a moderate effect, but an anecdotal $\mathrm{BF}_{10}\left(\mathrm{BF}_{10}=1.8, d=0.9\right)$ (Figures $\left.4-6\right)$.

In terms of correlations, only one pair of variables was found to have a better than anecdotal relationship. PLd $_{\text {ACC }}$ was observed to have a nearly perfect, decisive correlation to TAc, which can be seen in Figure 7 ( $r=$ 0.992, $\left.\mathrm{BF}_{10}=9,666\right)$. The subsequent Bayesian linear regression equation was revealed to be decisive with a $99 \%$ predictive association $\left(\mathrm{BF}_{10}=125, R^{2}=0.985\right)$, and can be written as:

Predicted TAc $=539.087+\left(2.285^{*}\left[\operatorname{PLd}_{\mathrm{ACC}}-214.5\right]\right)$

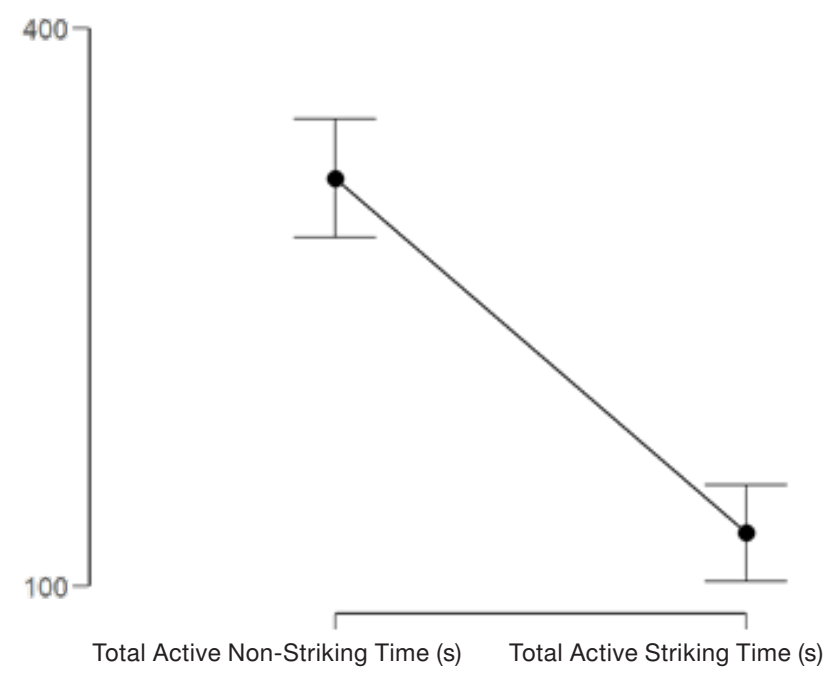

Figure 4. Difference between mean total active striking time (TStr) and mean total active non-striking time (TNStr) (error bars - 95\% CI) 


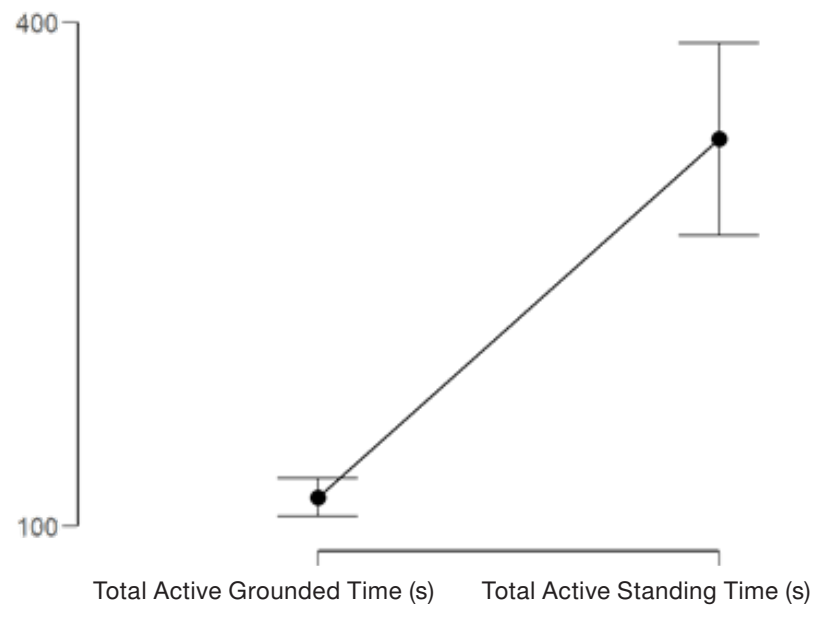

Figure 5. Difference between mean total active standing time (TSta) and mean total active grounded time (TGr) (error bars - 95\% CI)

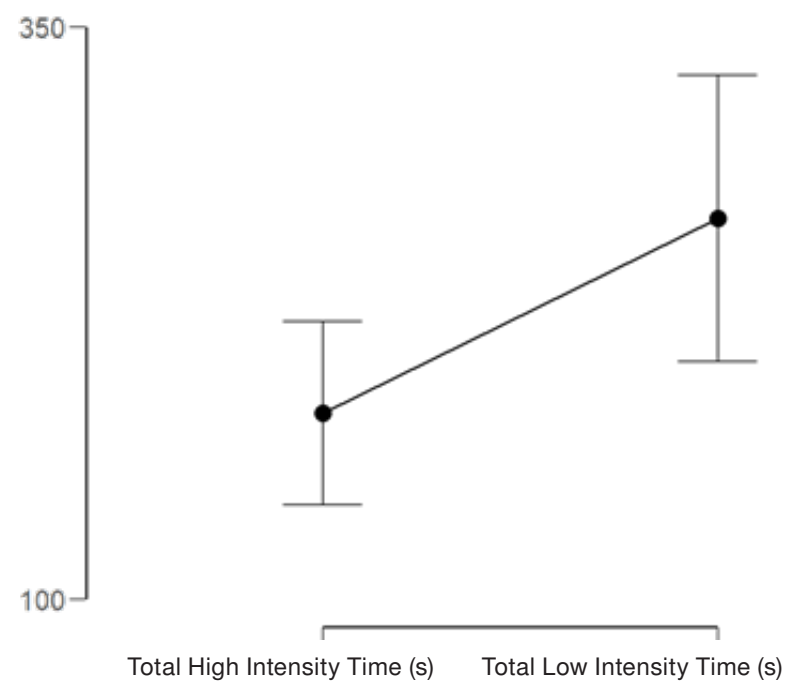

Figure 6. Difference between mean total high-intensity time (THI) and mean total low-intensity time (TLI) (error bars - 95\% CI)

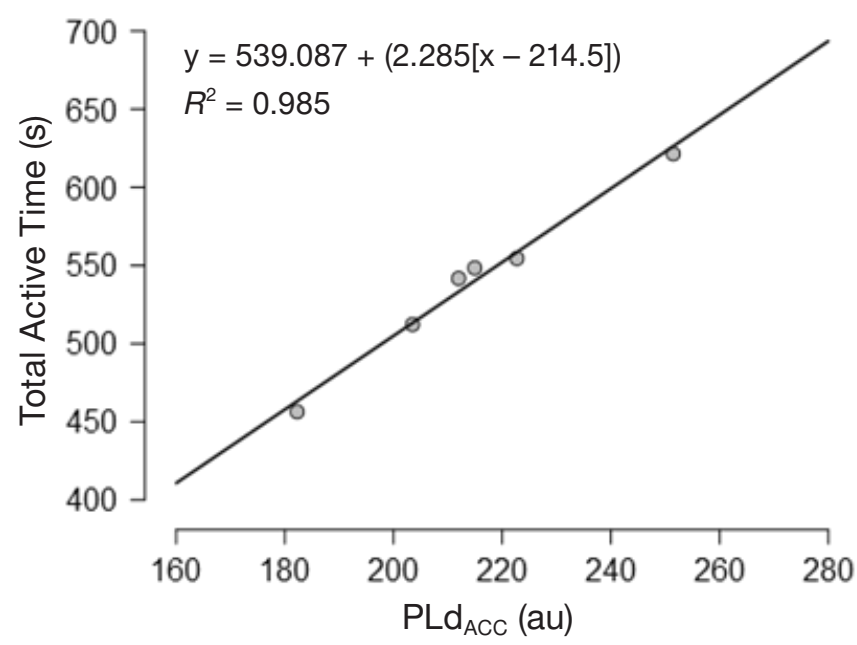

Figure 7. Relationship between accumulated Playerload $\left(\mathrm{PLd}_{\mathrm{ACC}}\right)$ and total active time

\section{Discussion}

The aim of this study was to provide a more detailed analysis of MMA sparring data than previously reported [17]. This was done to determine whether accelerometry and the Playerload metric had a potential role in monitoring the pacing of MMA participation. These new reanalyses have revealed some interesting and previously unreported findings that warrant further investigation.

The key result from this study is the relationship between PLd $\mathrm{ACC}_{\mathrm{A}}$ and TMA-derived measurements. The nearly perfect relationship between TAc and $\mathrm{PLd}_{\mathrm{ACC}}$ demonstrates that accelerometry is able to accurately track movement in a non-ambulatory, partially ground-based activity. Whilst this has been demonstrated in team contact sports, these studies primarily dealt with specific incidents and collisions such as tackling rather than movement overall [27-29]. PLd ${ }_{\mathrm{ACC}}$ does not seem able to distinguish between different intensities or modes of activity in MMA. Whilst TMA data showed statistically relevant differences between standing and grounded modes and different intensities, none of these variables alone was directly related to accelerometry. Whilst this demonstrates that $\mathrm{PLd}_{\mathrm{ACC}}$ is not as sensitive to changes in mode or intensity as TMA, it does show that accelerometry-derived measures are not biased towards or against striking or grappling focused movements. If $\mathrm{PLd}_{\mathrm{ACC}}$ was biased by striking movements, this would be revealed within the correlation tests against TSta or TStr. Equally, if there was a bias towards grappling movements, the results would have shown a greater correlation be-

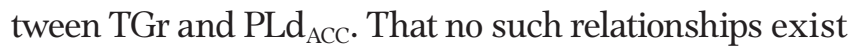
when TMA shows a clear delineation between modes, $\mathrm{PLd}_{\mathrm{ACC}}$ appears to be a potentially unbiased measure of overall external load for MMA. This supports the

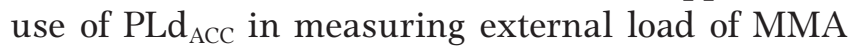
without the data being skewed by the technical performance differences inherent between divisions and genders [30], allowing its application across all anthropometric types. Though being able to distinguish between external load of striking versus grappling would be advantageous, this may not be an important factor in the measurement of pacing, as the information provided about the overall performance may still elicit key insights, as demonstrated in the following discussion.

Whilst the initial study's data (repeated here for clarity) showed that $\mathrm{PLd}_{\mathrm{ACC}}$ reduced in a linear fashion with each subsequent round, it can now be seen that there is a more complex pattern for this variable when viewed on a minute-by-minute basis. There is 
still a general downward trend as the bout progresses (Figure 3a), but there also appear spikes and troughs within the rounds themselves. Within the first round (minutes 1-5), there is a small decline in the $\operatorname{PLd}_{\mathrm{ACC}}$ of each minute until the $5^{\text {th }}$ minute, when there is a spike. This may reflect the participants' going through a 'feeling out' process, where they attempt to understand each other's tactical approach to the bout and decide upon their own strategy. This process seems to come to an end during the $5^{\text {th }}$ minute of the round, where PLd $\mathrm{ACC}_{\mathrm{ACC}}$ increases, potentially owing to each participant attempting to win the round through increased activity. The PLd $\mathrm{ACC}_{\mathrm{AC}}$ of this minute is also the highest recorded in the entire bout.

The second round (minutes 6-10) displayed a less consistent pattern. There was a steep decline in $\operatorname{PLd}_{\mathrm{ACC}}$ from the $1^{\text {st }}$ minute to the $2^{\text {nd }}$ minute of this round, followed by a sharp increase in the $3^{\text {rd }}$ minute. This appears to cause fatigue in many of the participants as there is a noticeable decline in $\operatorname{PLd}_{\mathrm{ACC}}$ over the final 2 minutes of the second round. It is at this stage of the bouts, however, that fitness and fatigue appear to play a role in the magnitude of $\mathrm{PLd}_{\mathrm{ACC}}$, as the variance around the mean (signified by the 95\% CI) increases markedly. This shows that some of the participants would have been capable of maintaining a relatively high work rate during this round, whilst others would have experienced a dramatic decrease during the final 2 minutes of the second round.

The third round (minutes 11-15) started with a similar PLd $\mathrm{ACC}_{\mathrm{AC}}$ to rounds 1 and 2, followed by a small decrease in the $2^{\text {nd }}$ minute of the round. In contrast to the increased work rate in the $3^{\text {rd }}$ minute of round 2 , however, there was a sharp decline in work rate in the $3^{\text {rd }}$ minute of round 3 . Whilst this was the lowest $\mathrm{PLd}_{\mathrm{ACC}}$ recorded in the bouts up to this point, there was again a relatively large variance around the mean, suggesting differing work rates and levels of fatigue. It is notable, though, that the upper limit of the 95\% $\mathrm{CI}$ is the lowest upper limit observed thus far during the bouts. This is possibly an indication that even the better conditioned participants were becoming fatigued by this stage of their bout. The $4^{\text {th }}$ minute of the third round displayed an increased $\mathrm{PLd}_{\mathrm{ACC}}$, again with a large variance around the mean, suggesting that some of the participants were able to increase their work rate in order to take control of the bout, whilst others were not. Whichever category the competitors fell into, the result in the $15^{\text {th }}$ and final minute of the bout appears to have been similar across the

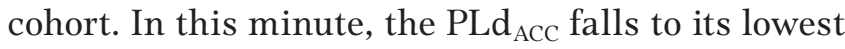
measurement and smallest variance of the entire bout.
Supported by the results of the statistical tests employed in this study, this strongly suggests that each of the participants was fatigued by this point and unable to maintain or even achieve their previous work rates.

Interestingly, the bout winners appear to adopt a slower pace than bout losers throughout (Figure 3b). This may be an indication of higher skilled participants being able to dictate the movements and intensities of their opponent. It may also imply that maintaining a lower pace throughout allows energy to be conserved enough to allow more successful application of key techniques related to winning and losing. What cannot be seen from these data is whether the participant's fitness levels have any effect on the pacing of the winners and/or losers. Determining whether this relationship exists would provide key support for the use of accelerometry in assessing the readiness of competitors during training. From a research standpoint, this could also offer a way to evaluate the efficacy of conditioning training methods amongst this population with ecological validity.

\section{Conclusion}

In conclusion, this study has expanded on the analyses conducted on these data previously [17] to provide a more detailed understanding of the external loads and patterns of MMA sparring bouts. The study has shown that $\mathrm{PLd}_{\mathrm{ACC}}$, and therefore the incidence of active, purposeful movements, changes on a minute-byminute basis during sparring, allowing the onset of fatigue to be highlighted. This suggests accelerometry may be used during competition preparation to measure work rates during training-based sparring bouts as a potential proxy for fatigue, readiness, and nonfunctional overreaching. This may also allow the assessment of the effects of, and adaptations to, physiological training amongst this population within an ecologically valid context, a use of accelerometry suggested in other sports [31]. The coach's understanding of the sport and their athlete must always be applied in conjunction with this proposed method to ensure the full context of the performance can be understood in relation to the data provided. PLd $\mathrm{AcC}_{\mathrm{AC}}$ cannot, however, distinguish between different intensities, standing/ grounded movements, or striking/non-striking actions. Whilst this limits accelerometry in determining the relative contributions to load of different actions in MMA, it appears to be useful in measuring overall external load during competition and it is argued this finding actually reduces the potential measurement bias of different combat styles and tactical approaches. 
This reanalysis was conducted to determine whether or not resources should be employed to fully validate the use of accelerometry for the field-based measurement of external load and pacing in MMA. The preliminary results reported here provide incentive for accelrometry application to be explored in new, large cohort studies in competitive and training environments.

\section{Limitations}

A key limitation of this study is the small sample size included. However, the Bayesian analyses reduce the effect of small sample sizes, particularly in the light of the strength of evidence provided [32]. Additionally, the the author's intentions throughout have been to provide suggestions of which areas display greatest potential for future, large cohort studies to be completed rather than present the data as definitive conclusions. A second limitation is that combat sports participation elicits psychophysiological differences between sparring and competition [33, 34]. As this study was completed in sparring, this must be considered an important caveat when reviewing these conclusions for use in an applied setting. This also highlights the need for such data to be collected in competitive settings to provide an accurate representation of external load in MMA.

\section{Acknowledgements}

The authors would like to thank each of the participants for giving up their time and taking part in the study, and also the MMA coaches for the provision of their time and use of their training facilities.

\section{Disclosure statement}

No author has any financial interest or received any financial benefit from this research.

\section{Conflict of interest}

The authors state no conflict of interest.

\section{References}

1. Abbiss CR, Laursen PB. Describing and understanding pacing strategies during athletic competition. Sports Med. 2008;38(3):239-252; doi: 10.2165/00007256200838030-00004.

2. De Koning JJ, Foster C, Bakkum A, Kloppenburg S, Thiel C, Joseph T, et al. Regulation of pacing strategy during athletic competition. PLoS One. 2011;6(1): e15863; doi: 10.1371/journal.pone.0015863.

3. Tucker R, Lambert MI, Noakes TD. An analysis of pacing strategies during men's world-record performances in track athletics. Int J Sports Physiol Perform. 2006;1(3):233-245; doi: 10.1123/ijspp.1.3.233.
4. Tucker R. The anticipatory regulation of performance: the physiological basis for pacing strategies and the development of a perception-based model for exercise performance. Br J Sports Med. 2009;43(6):392-400; doi: 10.1136/bjsm.2008.050799.

5. Waldron M, Highton J. Fatigue and pacing in high-intensity intermittent team sport: an update. Sports Med. 2014;44(12):1645-1658; doi: 10.1007/s40279-0140230-6.

6. Antoniettô NR, Dal Bello F, Carrenho Queiroz AC, de Carvalho PHB, Brito CJ, Amtmann J, et al. Suggestions for professional mixed martial arts training with pacing strategy and technical-tactical actions by rounds. J Strength Cond Res. 2019; doi: 10.1519/JSC.00000 00000003018.

7. Miarka B, Brito CJ, Amtmann J, Córdova C, dal Bello F, Camey S. Suggestions for judo training with pacing strategy and decision making by judo championship phases. J Hum Kinet. 2018;64:219-232; doi: 10.1515/ hukin-2017-0196.

8. Chaabène H, Franchini E, Miarka B, Selmi MA, Mkaouer B, Chamari K. Time-motion analysis and physiological responses to karate official combat sessions: is there a difference between winners and defeated karatekas? Int J Sports Physiol Perform. 2014;9(2): 302-308; doi: 10.1123/ijspp.2012-0353.

9. Tabben M, Sioud R, Haddad M, Franchini E, Chaouachi A, Coquart J, et al. Physiological and perceived exertion responses during international karate $\mathrm{ku}$ mite competition. Asian J Sports Med. 2013;4(4):263271; doi: 10.5812/asjsm.34246.

10. Bridge CA, Jones MA, Drust B. Physiological responses and perceived exertion during international taekwondo competition. Int J Sports Physiol Perform. 2009; 4(4):485-493; doi: 10.1123/ijspp.4.4.485.

11. Coswig VS, de P Ramos S, Del Vecchio FB. Time-motion and biological responses in simulated mixed martial arts sparring matches. J Strength Cond Res. 2016; 30(8):2156-2163; doi: 10.1519/JSC.0000000000001340.

12. Dos Santos DA, Miarka B, Dal Bello F, Carrenho Queiroz AC, de Carvalho PHB, Brito CJ, et al. 10 years on time-motion and motor actions of paired mixed martial arts athletes. Int J Sports Physiol Perform. 2019; 14(3):399-402; doi: 10.1123/ijspp.2018-0566.

13. Dal Bello F, Brito CJ, Amtmann J, Miarka B. Ending MMA combat, specific grappling techniques according to the type of the outcome. J Hum Kinet. 2019;67:271280; doi: 10.2478/hukin-2018-0081.

14. Worsey MTO, Espinosa HG, Shepherd JB, Thiel DV. Inertial sensors for performance analysis in combat sports: a systematic review. Sports. 2019;7(1):28; doi: 10.3390/sports7010028.

15. Del Vecchio FB, Bartel C, Galliano LM, Fukuda DH. Accelerometry use to study external load in combat sports: an example from taekwondo. J Phy Fit Treatment \& Sports. 2018;3(2):555608; doi: 10.19080/JPFMTS. 2018.03.555608. 
16. Hurst HT, Atkins S, Kirk C. Reliability of a portable accelerometer for measuring workload during mixed martial arts. J Athl Enhancement. 2014;3:5; doi: 10.4172/2324-9080.1000172.

17. Kirk C, Hurst HT, Atkins S. Measuring the workload of mixed martial arts using accelerometry, time motion analysis and lactate. Int J Perform Anal Sport. 2015; 15(1):359-370; doi: 10.1080/24748668.2015.11868798.

18. Meeusen R, Duclos M, Foster C, Fry A, Gleeson M, Nieman D, et al. Prevention, diagnosis, and treatment of the overtraining syndrome: joint consensus statement of the European College of Sport Science and the American College of Sports Medicine. Med Sci Sports Exerc. 2013;45(1):186-205; doi: 10.1249/MSS.0b013e318279 a10a.

19. Nedergaard NJ, Robinson MA, Eusterwiemann E, Drust B, Lisboa PJ, Vanrenterghem J. The relationship between whole-body external loading and body-worn accelerometry during team-sport movements. Int J Sports Physiol Perform. 2017;12(1):18-26; doi: 10.1123/ijspp. 2015-0712.

20. Edwards S, White S, Humphreys S, Robergs R, O’Dwyer N. Caution using data from triaxial accelerometers housed in player tracking units during running. J Sports Sci. 2019;37(7):810-818; doi: 10.1080/02640414. 2018.1527675.

21. Verheul J, Gregson W, Lisboa P, Vanrenterghem J, Robinson MA. Mechanical load monitoring: can accelerometers really estimate whole-body stresses? XXVII Isokinetic Medical Group Conference, Barcelona, June 2018.

22. Kirk C, Hurst HT, Atkins S. Comparison of the training loads of mixed martial arts techniques in isolated training and open sparring. J Combat Sports Martial Arts. 2015;1-2:1-6; doi: 10.5604/20815735.1174226.

23. Wetzels R, Wagenmakers E-J. A default Bayesian hypothesis test for correlations and partial correlations. Psychon Bull Rev. 2012;19:1057-1064; doi: 10.3758/ s13423-012-0295-x.

24. Hopkins WG. A scale of magnitudes for effect statistics. 2002. Available from: http://sportsci.org/resource/stats/ effectmag.html.

25. Field A. Discovering statistics using IBM SPSS Statistics, $4^{\text {th }}$ ed. London: Sage; 2013.

26. Knudson D. Significant and meaningful effects in sports biomechanics research. Sports Biomech. 2009;8(1): 96-104; doi: 10.1080/14763140802629966.

27. Roe G, Halkier M, Beggs C, Till K, Jones B. The use of accelerometers to quantify collisions and running demands of rugby union match-play. Int J Perform Anal Sport. 2016;16(2):590-601; doi: 10.1080/24748668. 2016.11868911.

28. Gastin PB, McLean OC, Breed RVP, Spittle M. Tackle and impact detection in elite Australian football using wearable microsensor technology. J Sports Sci. 2014; 32(10):947-953; doi: 10.1080/02640414.2013.868920.
29. Grainger A, McMahon JJ, Comfort P. Assessing the frequency and magnitude of match impacts accrued during an elite rugby union playing season. Int J Perform Anal Sport.2018;18(4):507-522;doi:10.1080/24748668.2018. 1496392.

30. Kirk C. Does anthropometry influence technical factors in competitive mixed martial arts? Hum Mov. 2018;19(2):46-59; doi: 10.5114/hm.2018.74059.

31. Gabbett TJ. Relationship between accelerometer load, collisions, and repeated high-intensity effort activity in rugby league players. J Strength Cond Res. 2015; 29(12):3424-3431; doi: 10.1519/JSC.000000000000 1017.

32. Wagenmakers E-J, Verhagen J, Ly A, Bakker M, Lee MD, Matzke D, et al. A power fallacy. Behav Res Methods. 2015;47(4):913-917; doi: 10.3758/s13428-014-0517-4.

33. Andreato LV, Follmer B, Celidonio CL, da Silva Honorato A. Brazilian jiu-jitsu combat among different categories: time-motion and physiology. A systematic review. Strength Cond J. 2016;38(6):44-54; doi: 10.1519/SSC. 0000000000000256.

34. Slimani M, Chaabène H, Davis P, Franchini E, Cheour F, Chamari K. Performance aspects and physiological responses in male amateur boxing competitions: a brief review. J Strength Cond Res. 2017;31(4):1132-1141; doi: 10.1519/JSC.0000000000001643. 